International Journal for Educational Integrity

\title{
Citations in search of a purpose: Source use and authorial voice in L2 student writing
}

\author{
Sharon McCulloch \\ Lancaster University, UK \\ samcculloch@mac.com
}

\section{Keywords:}

English as a second language, referencing, citation, intertextuality, plagiarism, epistemology, academic writing.

\begin{abstract}
Although much of the research into source use by international students has tended to focus on issues of plagiarism, there has recently been recognition that their difficulties in this respect may be more pedagogical than moral. However, much remains to be known about the nature of such students' source use. In order to throw light on the ways in which novice L2 writers use source material in their writing and to understand what difficulties they experience, this paper reports on a small case study involving a group of Japanese postgraduate students. Analysis of five Pre-Master's dissertations written by these students, as well as interviews conducted with the writers, revealed that they varied in their ability to handle source material effectively. In many cases, their use of source material appeared to be symptomatic of weak authorial stance and apparent lack of a clear argument. Based on these findings, the study concludes with the recommendation that instruction on the use of source material focus to a greater extent on its rhetorical function in constructing knowledge.
\end{abstract}

\section{Introduction}

Writing using source materials is a key aspect of academic literacy and a major means of assessment, particularly for those studying at postgraduate level. Because referencing source material is such a critical part of postgraduate writing, many student handbooks, style guides, departmental websites and English for Academic Purposes (EAP)courses include guidance on it. Despite this plethora of available guidance, however, it remains a common complaint that students, particularly those writing in a second language (Deckert, 1993; Gilmore, Strickland, Timmerman, Maher, \& Feldon, 2010; Marshall \& Garry, 2006), still produce work in which source material is so poorly referenced that it leaves the writers vulnerable to accusations of plagiarism (Campbell, 1990; Howard, 1995; Keck, 2006; Pecorari, 2010; Shi, 2010).

Various factors have been blamed for these problems, including cultural differences with respect to the ownership of ideas (Currie, 1998; Maxwell, Curtis, \& Vardanega, 2008; Pennycook, 1996), lack of awareness of expectations regarding plagiarism (Chanock, 2008; Roig, 1997; Shi, 2012; Wheeler, 2009), and pressures of time and expectations to perform (Bennett, 2005; Pecorari, 2010). However, understandings of what constitutes plagiarism vary even among academics (Roig, 2001; Shi, 2012), and many instances of inappropriate source use appear not to be simple cases of plagiarism as it is usually defined. Research since the mid-1990s (e.g. Howard, 1995, 1999; Pecorari \& Shaw, 2012; Pennycook, 1998 and many others) has therefore

The International Journal for Educational Integrity is available online at: http://www.ojs.unisa.edu.au/journals/index.php/lJEl/

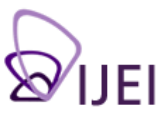


problematised the notion of plagiarism and recognised that both the causes and the effects of poor source use may be more complex than suggested by the above factors. Given that source use is such an essential feature of academic writing, and in view of the fuzzy nature of the concept of plagiarism, it is important to understand the ways in which students, and in particular international students, use source material, and the kinds of difficulties they experience even when their referencing does not, in the strictest sense, fall short of standards in terms of academic integrity.

With reference to extracts from the academic writing of a small group of Japanese postgraduate students, this case study sets out to explore the ways in which these students used source material in their Pre-Master's dissertations, with a particular focus on their difficulties in this respect.

\section{Understanding poor source use beyond plagiarism}

Plagiarism is usually defined as passing off the unacknowledged work of others as one's own, and is often linked with the concept of academic dishonesty. However, despite the implicit link to the idea of theft in such definitions, there has been a shift away from moralistic and culturally dependent understandings of plagiarism by international students, and research has suggested that the issue is a pedagogical matter rather than a moral one. For example, although students writing in their second language may appear more prone to plagiarism than L1 students, this may be related to limited linguistic dexterity (Campbell, 1990; Currie, 1998) or, for certain cultures, lack of familiarity with a dialogic model of writing (Gilmore, Strickland, Timmerman, Maher \& Feldon, 2010) as much as a belief that copying is acceptable. Many instances of source use that would qualify as plagiarism according to the above definition cannot easily be explained in terms of cheating. For example, instances in which a source is acknowledged but clumsily paraphrased, or where direct quotations are not marked as such despite being attributed seem far more common than cases of outright copying (Abasi, Akbari, \& Graves, 2006; Chanock, 2008; Ivanič, 1998; Pecorari, 2010). This suggests that some of the more frequent problems manifested in the source use of second language writers are due to something other than the intention to deceive.

Furthermore, plagiarism is only one aspect of inappropriate source use. Aside from the kind of grey areas associated with patchwriting (Howard, 1995), it is also possible to avoid plagiarism and yet still fail to use source material effectively. For example, although research in the area is limited, some evidence suggests that L2 students tend to rely too heavily on direct quotation in their writing. Borg (2000), for example, found that L2 students used direct quotation more often than L1 students. Campbell (1990) also found this to be the case for students with lower English proficiency, although those with high levels of proficiency (as measured by a Scholastic Aptitude Test) used less quotation than native English speakers. Anecdotal evidence and some studies (Petrić, 2012; Schembri, 2009) indicate that excessive quoting is generally frowned upon, but given the emphasis on acknowledging intellectual property rights in much of the advice on referencing, inexperienced students may be surprised, having gone to great lengths to avoid accusations of plagiarism by citing meticulously, to be told that peppering their writing with quotations is also unacceptable.

The problem with excessive quoting may be not the quantity per se but that, unless it is done skilfully, it can limit the extent to which ideas can be re-contextualised for a new rhetorical purpose. Source material should not simply be reproduced and reported, but rather reshaped and put to the service of one's own unique argument. In this way, paraphrasing may be an artefact of the reconceptualisation involved in constructing knowledge in academia. Where students rely too heavily on quotation, therefore, this may indicate a problem relating to their own sense of purpose in their writing rather than laziness or reluctance to take the trouble to paraphrase. It is worth 
noting, however, that the extent to which direct quotation is considered acceptable varies, along with other citation norms, from discipline to discipline (Hyland, 1999), and it is important to consider how quotations are used to support a writer's argument.

Another way in which source use can be problematic without constituting plagiarism is through lack of evaluation. A common complaint about novice L2 writers is that they attribute too much authority to their sources and fail to take a sufficiently evaluative stance towards them (Pecorari, 2003; Petrić, 2007; Thompson, 2005). This may lead to accusations that their writing is primarily a collection of others' views rather than a coherent argument bolstered by reference to others' work. Such a problem may be influenced to a certain extent by culture and previous learning experiences in that students from societies in which scholars and experts are afforded high status may be reluctant to critique their sources (see, for example, Carroll, 2007; Dorji, 2001; Sowden, 2005). However, the phenomenon is not limited to Asian students. Abasi and Graves (2008), for example, found that students from South America and Europe also lacked awareness of the need for criticality and evaluation in writing.

It is important to note that rhetorical expectations in terms of argumentation, structure and stance in academic writing vary from culture to culture (e.g. Duszak, 1994; Hinds, 1987 ) and the preferences of the Anglophone community are not necessarily the norm. However, L2 students writing in the UK or other English-speaking contexts must meet the expectations of the academic discourse communities in which they find themselves since failure to do so may result in them failing their degree.

\section{The link between epistemology and source use}

The need to take an evaluative stance towards source material and to recontextualise such material to fit one's own purpose is closely linked to issues of epistemological stance and authorial identity (Chandrasoma et al., 2004). Academic discourse is both intertextual and dialogic in that it builds upon and develops existing ideas, and must anticipate others' responses in turn (Chanock, 2008). For this to happen, the voices of others must be invoked through citation. In this sense, the referencing of sources is both characteristic of the way in which knowledge is socially constructed and an inherent aspect of building a written argument in academia and not, as many style guides and university policies on the subject might suggest, simply a surface feature relating to notions of copyright.

Novice writers, particularly international students who lack experience of this dialogic and argumentative tradition of writing, may not always be aware of the symbiotic relationship between the referencing of sources and epistemology. Abasi et al. (2006), for example, found that international Masters students at a Canadian university tended to see their sources as "repositories of knowledge that could not be contested" (Abasi et al., 2006, p. 111) and this led them to commit inadvertent plagiarism. Similarly, Penrose and Geisler (1994) examined the reading-to-write process and the resulting texts of an L1 freshman and doctoral student, and found that the freshman appeared to follow an information-transfer approach (p. 507) and referred to her sources as though they presented "facts". In contrast, the doctoral student treated the source texts as a set of competing claims and referred to the source authors by name far more in both his reading and his writing.

The emphasis in much of the available guidance on referencing sources tends to lie on the mechanical aspects of citation rather than its role in constructing knowledge, and this may give students the false impression that good source use can be achieved simply by following formatting rules. For example, style guides such as those of the APA and MLA (American Psychological Association, 2009; Gibaldi, 2008), provide extensive and detailed information on punctuation, formatting and the order of elements, but make little mention of the rhetorical function of citation. 
Likewise, the focus in many degree programmes is on content knowledge rather than epistemology, and the rhetorical construction of knowledge may seldom be discussed explicitly (Abasi \& Graves, 2008). Even EAP courses and textbooks may not foreground such matters (Abasi et al., 2006), often approaching paraphrasing and summarising in terms of making surface changes at sentence level, and neglecting the negotiated nature of the claims being cited.

Overall, evidence does suggest that international students tend to see referencing mainly as a means of protecting themselves against accusations of plagiarism, while their professors see it as an attribute of authoritative writing (Abasi \& Graves, 2008). It seems likely that incomplete understandings of the need to take an authorial stance may contribute to the clumsy handling of source material, and it is this that forms the focus of this study.

\section{Method}

The aim of this case study is to explore the ways in which a group of five Japanese postgraduate students struggle to use source materials effectively in their PreMaster's dissertations. Instances of ineffective source are examined and contrasted with instances of more skillful handling of sources in an attempt to understand the types of difficulties these writers experience. In particular, I consider the extent to which their problems in referencing sources may be related to lack of authorial voice rather than poor citation skills per se.

\section{The participants}

The participants in this study were five Japanese students near completion of a fulltime Pre-Master's Programme at a private college in Tokyo. The aim of the programme was to prepare the students for Social Science Master's degrees in the UK, and it included subject modules on Development Studies and Applied Linguistics, as well as EAP support modules such as Academic Writing Skills and Research Methods. All students received the same instruction on academic writing and citation, and all classes were conducted and assignments completed in English. Successful completion of the course was a condition of acceptance to the students' chosen university in the UK and involved several written assignments, a final exam and a 5,000-word dissertation. All the students spoke Japanese as their first language, had completed an undergraduate degree at a Japanese university, and had achieved an overall IELTS score of at least 6 at the beginning of the programme.

\section{The data}

The dissertations averaged 5,000 words in length to make a total corpus of around 25,000 words. The grades and feedback the students received for their dissertations were also collected, and a semi-structured text-based interview was conducted with each student to discuss selected references to source material.

The students' names (pseudonyms are used), disciplines and dissertation grades are shown in Table 1 below: 
Table 1:

The writers, disciplines, and grades of each dissertation

\begin{tabular}{|l|l|l|}
\hline Writer & Discipline & Dissertation grade \\
\hline Hajime & Applied Linguistics/TESOL & $78 \%$ \\
\hline Saori & Applied Linguistics/TESOL & $66 \%$ \\
\hline Mai & Development Studies & $64 \%$ \\
\hline Aiko & Development Studies & $48 \%$ \\
\hline Kai & Development Studies & $42 \%$ \\
\hline
\end{tabular}

Three of the dissertations achieved pass grades of $78 \%, 66 \%$, and $64 \%$, and two received fail grades of $48 \%$ and $42 \%$. The extracts from the students' work presented in this study are all as per the original, and no changes or corrections have been made to them.

\section{Data analysis}

References to source material were identified by searching the dissertations electronically for canonical citation forms such as a date in brackets and Latin terms such as ibid. Further searches were then conducted for names of authors, third person pronouns and terms such as these researchers. The texts were then checked manually to ensure that all names thus identified were in fact references to source material and that nothing had been missed.

Once identified, the number and type of references to source material were then counted. Specifically, references to source material were analysed in terms of whether they were presented via direct quotation or paraphrase/summary. Where direct quotations were used, they were classified as either short quotations integrated into the body text using quotation marks or quotations of more than three lines, which would, according to the Harvard referencing system the students were using, be indented in block format. References to source material that seemed problematic in terms of under- or over-referencing, ambiguous attribution of information, or unclear purpose were selected for closer examination to consider issues such as the type of authorial and epistemological stance expressed.

The grades and feedback the students received for their dissertations were collected in order to provide a general sense of how successful the text had been in creating the right impression and what role, if any, the handling of source material played in this. Clearly the use of source material is just one of many factors taken into consideration when awarding grades, but it does seem likely that major problems with referencing, as well as issues such as the failure to evaluate source material, would be mentioned in the marker's comments.

In addition to interpreting the students' referencing practices from an etic perspective (as seen by an external researcher), I aimed to gain insight into their views on source use from an emic perspective (as described by the participants themselves). Therefore, I used text-based, semi-structured interviews (Odell, Goswami, \& Herrington, 1983) to ask the students about their use of source material. The students were invited to comment on specific instances of source use in their dissertations. Questions included, for example, Why did you decide to quote here? and Do you agree with this author's view? To avoid influencing the participants' writing decisions or causing them undue anxiety about the appropriateness of their referencing, these interviews were conducted only after the students had submitted and received 
feedback on their dissertations. This means that their comments may reflect the markers' judgments on their work as well as their own. In the section that follows, notable features of these students' use of source material are discussed, with reference to extracts from their dissertations, interviews and, where relevant, grades awarded.

\section{Results and discussion}

Use of direct quotation

As Table 2 shows, these students used direct quotation for an average of just under $17 \%$ of their references to source material, with considerable variation between students. Kai used quotation the least, but rather than indicating that he used effective paraphrasing instead, this is probably a reflection of the low number of references to source material of any kind in his work. He used the lowest number of citations of anyone in the group (just 4.8 per 1,000 words), and the figure of $4.5 \%$ shown in Table 2 represents just one single quotation.

Table 2:

Percentage of source material presented via direct quotation

\begin{tabular}{|l|l|l|l|l|l|l|}
\hline Type of citation & Hajime & Saori & Mai & Aiko & Kai & Average \\
\hline Short quote & $18.4 \%$ & $2.1 \%$ & $10.3 \%$ & $14 \%$ & $4.5 \%$ & $9.9 \%$ \\
\hline Extensive quote & $5.3 \%$ & $8.3 \%$ & $2.9 \%$ & $18 \%$ & 0 & $6.9 \%$ \\
\hline
\end{tabular}

The student with the highest number of quotations was Aiko, who used this method of presenting $32 \%$ of her citations. Although she used direct quotation more than the others in this group, this does not necessarily indicate overuse. It is difficult to draw conclusions about genre norms since there is a lack of research on quotation in student writing and considerable variation between disciplines, but Aiko's use of quotation is lower than that of the 16 MA students in Petrić's study (2012), who used it for almost $37 \%$ of their citations. This might indicate that the amount of quotation itself is not particularly excessive.

As noted earlier, it is important to consider not just how many quotations are used, but also how effectively they are presented and deployed. The extract of Aiko's work below shows that some of her direct quotations are neither necessary nor helpful in building her argument:

\section{Extract D.1, Aiko}

Furthermore, according to Willett (2003, p75) in her book Participatory monitoring of humanitarian mine action: Giving voice to citizens of Nicaragua, Mozambique and Cambodia reported that "Even a government with a limited revenue base must establish its financial priorities". Besides, she added that "it is clear that mine action has a comparatively low priority" because "demining and mine action as traditionally conceived may not appear to be a cost-effective use of funds".

Aside from the syntactic problem of combining the reporting adjunct according to with the reporting verb reported, the quotations in this extract fail to support the student's argument because they do not serve any obvious purpose. Aiko has used quotation fragments in the form of multiple short snippets of borrowed material integrated into a single sentence. Petrić (2012) found such short fragments to be more common in highly-rated MA dissertations. However, in Aiko's work they are not used to present terminology or expressions that have any special meaning, nor do they illustrate any 
particular point being made by her. Instead, the quoted text appears to contain the main point - that mine clearing has not been prioritised for financial reasons. The impression created by this is that Aiko is endorsing Willett's argument rather than Willett's comments supporting Aiko's argument.

When I asked Aiko about her use of quotation here, she explained that she had attempted to be critical in her choice of source material and chosen a source that she both agreed with and felt was reliable:

\section{Extract Int.1, Aiko}

I am agree with this. I know it's true, so I thought that because it's good data, I mean it's reliable source, it's OK.

However, it is telling that she bases her agreement with the cited source on her perception that it represents the truth. This suggests that Aiko's epistemological perspective is similar to that of the less experienced students in Abasi et al. (2006) and Penrose and Geisler's (1994) studies in that she saw her sources as facts to be collated and reported rather than claims to be discussed and evaluated.

The majority of the quotations Aiko uses are not short fragments, but lengthy chunks of text extending over more than three lines. These are mostly made up of tables copied wholesale from the source and pasted into the Results and Discussion section of her dissertation. An example is shown in Extract D.2 below:

Extract D.2, Aiko

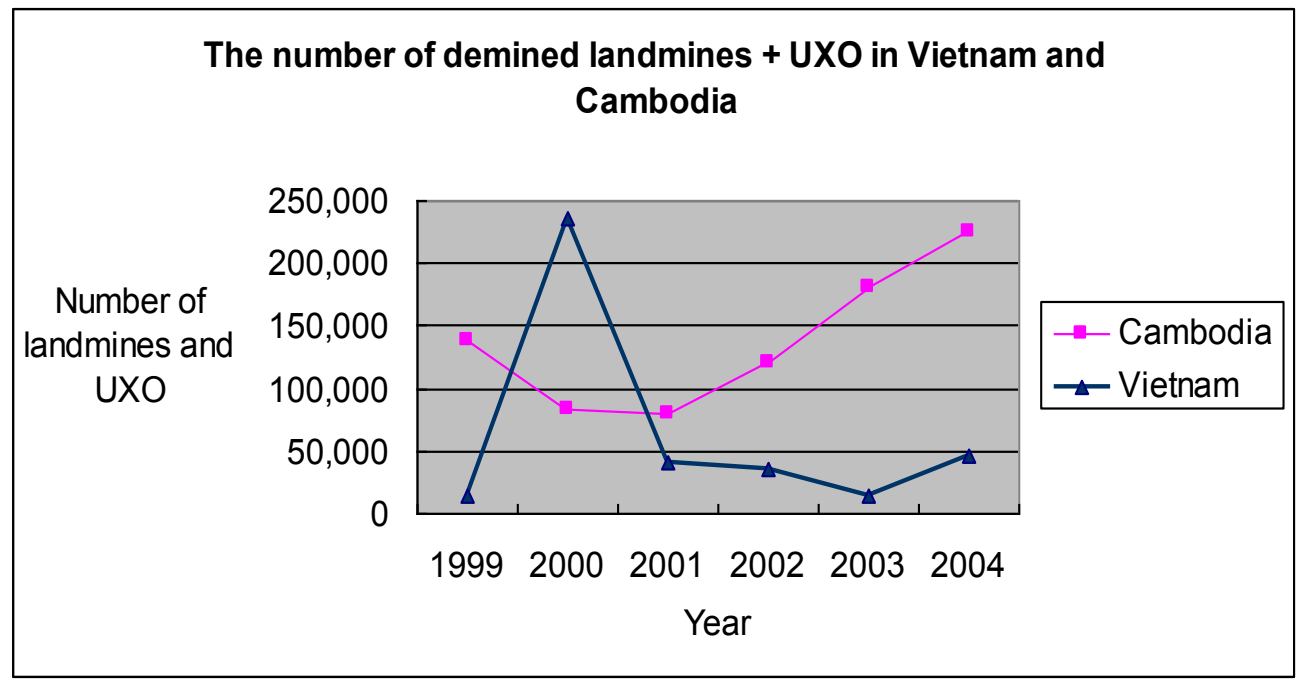

(Source: Landmine Monitor Report (2000-2005) Cambodia, Vietnam

The number of demined landmines and UXO in Vietnam and Cambodian is shown in table 1 . The numbers which were shown in this table were reported not by governments but by Non Governmental Organisations such as ICBL. In this table, the number of landmines which removed from fields gradually increases in Cambodia from 2001 to 2004.

Aiko used this method of copying complete, unaltered tables from the same source four times in a relatively short, 991-word section of her dissertation. The problem with such use of source material is not only the amount of quotation but also the 
placement of it. Although references to source material are increasingly found throughout research papers and not limited to the review of literature (Swales, 1990; Hyland, 1999), one would still expect the Results and Discussion section of a dissertation to focus largely on the findings of the current writer. Petrić (2012) has noted that the use of quoted material in the Results and Discussion section can be positive in that it may indicate not only understanding of the source material, but also an ability on the part of the writer to apply it to their own data. However, Aiko does not apply any theory or terminology to her own data and in fact the quoted material seems to be substituting rather than supporting her own findings. This impression is reinforced because Aiko did not cite any other sources in this section of her dissertation and so did not compare the findings of the Landmine Monitor Report with anything else. The inclusion of so many unadapted tables in the Results and Discussion section was criticised by her tutor on the grounds that the "results" being discussed were not the results of Aiko's own research, but those of the cited source.

Although Aiko's use of direct quotation suggests that she was reduced to endorsing someone else's argument rather than creating her own, it is important to note that direct quotation is not necessarily indicative of poor source use. One student in this group, Hajime, presented almost $24 \%$ of his source material in the form of direct quotation, far more than some of the lower scoring students, and yet managed to do so quite effectively to support his argument.

Hajime's dissertation aimed to find out how many basic clause types there are in English. To do this, he examined terminology used by a range of grammarians, which necessitated the use of many short quotations in order to illustrate his point, as seen in Extract D.3 from his dissertation:

\section{Extract D.3, Hajime}

Hornby's Oxford Advanced Learner's Dictionary (2000: 215) defines a clause as "a group of words that includes a subject and a verb, and forms a sentence or part of a sentence," and Leech and Svartvik (2002: 258) state "A clause can be analysed into five different types of clause elements: $S=$ Subject, $V=$ Verb, $\mathrm{O}=$ Object, $\mathrm{C}=$ Complement, $\mathrm{A}=$ Adverbial."

Like Aiko in Extract D.1, Hajime uses several quotation fragments within one sentence. However, the impression created is one of purposeful comparison of the cited authors' claims. Without quoting these authors directly, Hajime would have been unable to clearly differentiate between one use of terminology and another and his analysis would have been weakened. Hajime's use of source material here suggests that he has the confidence to treat the various grammarians' views as authored claims rather than absolute truths, and his inclusion of these quotations enables him to advance his own claim to knowledge.

The extract above supports the view that rather than being something to be universally avoided, direct quotation can support certain types of argumentation, particularly those that require definitions or comparison of terminology. It appears that the key to successful quotation is not using it sparingly, but using it to stake a claim to knowledge by comparing and contrasting the claims of others, rather than to replace one's own argument.

\section{Use of paraphrased or summarised source material}

It is not only through direct quotation that these students struggled to use source material appropriately. Just as quoting directly is not necessarily a hallmark of poor source use, the use of paraphrase or summary is not necessarily an indicator of good source use. 
One of the students whose dissertation received a fail grade, Kai, used paraphrase and summary for the vast majority $(83 \%)$ of his citations, yet this did not always lead to successful deployment of source material. Extract D.4, a lengthy passage

containing information about policy decisions is one example of this:

\section{Extract D.4, Kai}

There are many causes of the conflict in Sri Lanka. JBIC (2002) reports on root causes which had been existed before 1983 when the conflict happened. Firstly, language policy is one of the most important causes of the conflict. In 1956, government decided that only Singhalese would be the official language and Tamil who are the minority in Sri Lanka and cannot use Sinhalese, lost the opportunity to participate in Singhalese society which represents the main part of whole society. Thus that became a disadvantage for the Tamils. A further point is the university entrance policy. Criteria of entrance examination of university for Tamils were set higher than Singhalese and Tamil had to get a higher score than Sinhalese to enter university. As a result, the enrolment rate of university of Tamils went down and equity to have education was lost. This matter influences the employment rate of Tamils directly because if people could not have enough education, they cannot get jobs. Tamils who lost job tend to volunteer in the army, the militia, or guerrilla organizations.

Only the initial point, that the causes of the conflict have been analysed, has been attributed even though all of the supporting details in this passage also appear to be attributable to JBIC. The information about language policy, university entrance policy, employment opportunities, and the recruitment of Tamils into military organisations can be found in the JBIC report cited by Kai, listed in the same order as above, in a table entitled "Root Causes of Conflict (before 1983)". Although he has taken only selected information from this table and woven them into his own syntax, the order in which the information is presented and the fact that several strings of words above are identical to those in the source, including the 9-word string "volunteer in the army, the militia, or guerrilla organizations" (underlined), point to JBIC as the source for the whole paragraph. Kai seems to have thought it sufficient to attach one citation to the general topic and expect the reader to infer the same source for everything that follows. The under-referencing here could, by some measures, be construed as plagiarism, yet it clearly does not stem from any intent to deceive. Rather, it seems more likely that it results from Kai's attempts to build his discussion around the cited author's argument rather than constructing a clear claim to knowledge of his own. Rather than using source information to support his own point, this writer simply describes and appears to endorse the views of his source.

With respect to the evaluation of source material, these students also experienced a number of difficulties. In Extract D.5, Kai places his reference in a prominent subject position using integral citation, but then fails to exploit the evaluative potential thus opened up:

\section{Extract D.5, Kai}

Bercovitch (1996) describes that the conflict emerges fragmentation of societies and communication breakdowns between segments of society. Although ceasefire is established in 2002 by mediation of Norway government, these negative elements still remain in society and it is still unstable and there are many elements of recurrence of the conflict. In this context, in Sri Lanka, people need human security rather than state security and it is needed to reduce confrontation and distrust between different ethnic groups. 
Because of the prominence of the cited author in Extract D.5, the reader is led to expect that some kind of analysis or evaluation of Bercovitch's claim will follow, but this expectation is not fulfilled and the argument seems instead to move on to a more general point about the need for human security. Given the apparent lack of importance of Bercovitch's particular contribution to the wider argument being developed here, it might have been more effective to minimise the role of the cited author by using non-integral citation, as seen in the suggested revision below:

\section{Extract D.5: Suggested revision}

Because conflict emerges fragmentation of societies and communication breakdowns between segments of society (Bercovitch 1996), these negative elements still remain in society and it is still unstable and there are many elements of recurrence of the conflict despite the ceasefire established in 2002 by mediation of Norway government. In this context, in Sri Lanka, people need human security rather than state security and it is needed to reduce confrontation and distrust between different ethnic groups.

Although the suggested revision of Extract D.5 still contains linguistic errors, and despite the need for minor syntactic changes (underlined) to accommodate the nonintegral citation, it represents a more effective piece of argumentation than the original version, mainly because the source material appears to support the writer's argument rather than vice-versa.

A similar problem with evaluation is seen in Extract D.6, from Saori's dissertation, where the reader is again led to expect either disagreement with or further discussion of these authors' claims:

\section{Extract D.6, Saori}

According to Ellis and Barkhuizen (2005), in investigating learner language, it is important to collect reliable and valid samples from actual speech or writing because the learner's language competence can be measured by their language performance. Therefore, it is necessary to obtain actual conversation samples from the learner in order to research about the use of communication strategies.

By presenting the source material in this way, the writer seems to imply that Ellis and Barkhuizen have something particularly insightful to say here, when in fact the cited proposition is more or less common knowledge, at least within the disciplinary community. This creates the impression that Ellis and Barkhuizen are experts, while Saori's conclusion that actual speech samples are necessary is portrayed not as common sense, but as reliant on their wisdom. This appears to be a case of overciting, perhaps as a result of uncertainty over the rather nebulous concept of common knowledge (Thompson, 2005) or the desire to appear knowledgeable, which has itself been associated with lack of authorial voice (Abasi et al., 2006).

On occasions, source material was used in such a way that it obscured the attribution of claims and led to ambiguity over whose voice was being represented. In Extract D.7, from Mai's dissertation, it is unclear whether it is Mai or Orjuela who believes that NGOs' activities are piecemeal. 
Extract D.7, Mai

Orjuela (2005) also describes this point. Although NGOs should adjust their programmes to meet local community needs, they have made their plan to adjust desire of the aid agencies. Donors tend to need quick and visible results, so NGOs make plans which produce short-term impacts to promote aid. These kinds of activities tend to be piecemeal and cannot be aid for local community.

The impression created here is that Mai was not in fact constructing her own argument, but simply describing her source's position. When I asked Mai in interview whether this information originated from her or her source, she said that she had found it in "that book" even though the source by Orjuela is listed in her bibliography as an article published in the Journal of Peace and Democracy in South Asia:

\section{Extract Int.7, Mai}

"This information comes from that book. I read about what NGO do there."

This kind of generic naming of sources is similar to that of the less experienced student in Penrose and Geisler's (1994) study, and may be indicative of an underdeveloped perception that claims are authored by individuals. I asked Mai whether she agreed with Orjuela's point here. Her reply is shown in Extract Int.8:

\section{Extract Int.8, Mai}

"Mmmm ... I don't know. I think so. To be honest, I just included all what ... all information I had because I did not have a clear idea. I felt so unsure."

Mai's answer indicates that she did not have a clear sense of knowing what to say in her writing. These extracts together also suggest that her poor referencing is a side effect of her lack of authorial voice rather than the reverse. In other words, Mai's poor use of source material is a symptom of an underlying problem rather than the cause of the problem per se. It also implies that Mai was unable to take a critical stance towards her source because she saw it as a source of truth rather than one of many possible claims. In the absence of a clear sense of having something to say, Mai put the claims of her source authors at the centre of her work, and this is reflected in her poor referencing.

\section{Conclusions}

Although none of these students were accused of plagiarism, they did experience a number of difficulties with the use of source material. These included treating source claims as uncontestable truths, failing to take an evaluative stance towards sources, and placing too much emphasis on sources at the expense of their own argument.

The analysis revealed that the students sometimes used inappropriate direct quotations, particularly when this involved the inclusion of large chunks of quoted text without accompanying evaluation. In other cases, the problem was less related to the form of the quotations, as their rhetorical function within the emerging argument. Specifically, both low- and high-scoring writers used multiple quotation fragments, but with different results.

When they used their own words to paraphrase/summarise material from sources, some of these students had difficulties placing their own claims to knowledge at the heart of their writing and tended to allow their sources to speak for them. Again, these difficulties could not, in most cases, be described as plagiarism, nor do they seem to stem from poor citation skills per se. It appears that this poor source use is in fact 
related to the fact that, in constructing their arguments, these students gave centrality to their sources, with the result that their own arguments were marginalised.

Many of these difficulties appear to relate, at least in part, to these students' failure to view knowledge as socially constructed and thus to position themselves with an appropriate authorial voice in their writing. An association between the ability to build a unique argument and referencing has also been noted by Pecorari (2010), who found that writers who used sources more transparently also used them to advance a clear argument or sense of purpose. The findings of this case study also lend some support to the view that much of what passes for borderline plagiarism may in fact be a symptom of underdevelopment of authorial voice (Lea \& Street, 1998).

\section{Implications}

Although the problems manifested in these students' use of source material cannot be generalised from such a small case study, the findings do suggest that the mere absence of plagiarism does not necessarily indicate that novice writers are able to deploy sources well. The problems associated with poor use of sources are multidimensional. Given the centrality of referencing in academic writing, it is important that students learn how to use source materials skillfully in the service of their own arguments. To do this, they need information about the dialogic nature of writing and the rhetorical functions of citation within it. A more explicit link between the construction of knowledge in academia and the use of source material would be helpful in this regard.

With respect to direct quotation, the results of this case study suggest that advising students not to rely heavily on quotation may understate the complexity of what it means to deploy sources well, since the effectiveness of quoted material depends on how it is integrated into the text and the extent to which it is recontextualised to fit the writer's current purpose. Instruction on referencing, particularly at postgraduate level could therefore usefully include information on the different ways in which quotation can be integrated within the writer's text and, more importantly, why quotation might be employed.

With regard to source material presented in the writers' own words, this was associated with both under- and over-referencing, as well as problematic placement of citations within the text. This underlines the fact that students' difficulties with referencing may not be solved simply by using their own words, even though this might avoid the problem of plagiarism.

One way of addressing these difficulties would be to encourage students to engage in the rhetorical analysis of samples of academic writing, paying close attention to the ways in which referencing is used to advance the writer's argument. Explicit discussion of the many reasons why writers cite source material (see, for example, Petrić, 2007; Harwood, 2009) would also be helpful in shifting attention away from a sole emphasis on issues of intellectual property and breach of copyright. 


\section{References}

Abasi, A. R., Akbari, N., \& Graves, B. (2006). Discourse appropriation, construction of identities, and the complex issue of plagiarism: ESL students writing in graduate school. Journal of Second Language Writing, 15(2), 102-117.

Abasi, A. R., \& Graves, B. (2008). Academic literacy and plagiarism: Conversations with international graduate students and disciplinary professors. Journal of English for Academic Purposes, 7(4), 221-233.

American Psychological Association (2009). Publication manual of the American Psychological Association (6th ed.). Washington, DC: American Psychological Association.

Bennett, R. (2005). Factors associated with student plagiarism in a post-2992 university. Assessment \& Evaluation in Higher Education, 30(2), 137-162.

Borg, E. (2000). Citation practices in academic writing. In P. Thompson (Ed.), Patterns and perspectives: Insights into EAP writing practices (pp. 27-45). Reading: University of Reading.

Campbell, C. (1990). Writing in others' words: Using background reading texts in composition. In B. Kroll (Ed.), Second language writing: Research insights for the classroom (pp. 211-230). Cambridge: Cambridge University Press.

Carroll, J. (2007). A handbook for deterring plagiarism in higher education (2nd ed.). Oxford: Oxford Centre for Staff and Learning Development.

Chandrasoma, R., Thompson, C. \& Pennycook, A. (2004). Beyond plagiarism: Transgressive and non-transgressive intertextuality. Journal of Language, Identity and Education, 3(3), 171-93.

Chanock, K. (2008). When students reference plagiarised material - what can we learn (and what can we do) about their understanding of attribution? International Journal for Educational Integrity, 4(1), 3-16.

Currie, P. (1998). Staying out of trouble: Apparent plagiarism and academic survival. Journal of Second Language Writing, 7(1), 1-18.

Deckert, G. D. (1993). Perspectives on plagiarism from ESL students in Hong Kong. Journal of Second Language Writing, 2(2), 131-148.

Dorji, L. (2001). Japanese students' learning styles and British TEFL teaching styles. In K. Gray, M. A. Ansell, S. Cardew \& M. E. Leedham (Eds.), The Japanese learner: Context, culture and classroom practice (pp. 59-69). Oxford: Department of Continuing Education, University of Oxford.

Duszak, A. (1994). Academic discourse and intellectual styles. Journal of Pragmatics, 21(3), 291-313.

Gibaldi, J. (2008) MLA style manual and guide to scholarly publishing (3rd ed.). New York: Modern Language Association.

Gilmore, J., Strickland, D., Timmerman, B., Maher, M., \& Feldon, D. (2010). Weeds in the flower garden: An exploration of plagiarism in graduate students' research proposals and its connection to enculturation, ESL and contextual factors. International Journal for Educational Integrity, 6(1), 13-28. Retrieved December 4, 2011, from http://www.ojs.unisa.edu.au/index.php/lJEl/article/view/673/502

Harwood, N. (2009). An interview-based study of the functions of citations in academic writing across two disciplines. Journal of Pragmatics, 41(3), 497-518.

Hinds, J. (1987). Reader versus writer responsibility: A new typology. In U. Connor \& R. Kaplan (Eds.), Writing across languages: Analysis of L2 text (pp. 141-152). Reading, MA: Addison-Wesley.

Howard, R. M. (1995). Plagiarisms, authorships, and the academic death penalty. College English, 57(7), 788-806.

Hyland, K. (1999). Academic attribution: Citation and the construction of disciplinary knowledge. Applied Linguistics, 20(3), 341-367.

Ivanič, R. (1998). Writing and identity: The discoursal construction of identity in academic writing. Amsterdam: John Benjamins. 
Keck, C. (2006). The use of paraphrase in summary writing: A comparison of $L 1$ and L2 writers. Journal of Second Language Writing, 15(4), 261-278.

Lea, M. R., \& Street, B. V. (1998). Student writing in higher education: An academic literacies approach. Studies in Higher Education, 23(2), 157-172.

Marshall, S., \& Garry, M. (2006). NESB and ESB students' attitudes and perceptions of plagiarism. International Journal for Educational Integrity, 2(1), 26-37.

Maxwell, A., Curtis, G. J., \& Vardanega, L. (2008). Does culture influence understanding and perceived seriousness of plagiarism? International Journal for Educational Integrity, 4(2), 25-40.

Odell, L., Goswami, D., \& Herrington, A. J. (1983). The discourse-based interview: A procedure for exploring the tacit knowledge of writers in non-academic settings. In P. Mosenthal (Ed.), Research on writing: Principles and methods (pp. 221236). New York: Longman.

Pecorari, D. (2003). Good and original: Plagiarism and patchwriting in academic second-language writing. Journal of Second Language Writing, 12(4), 317-345.

Pecorari, D. (2010). Academic writing and plagiarism: A linguistic analysis. London: Continuum.

Pecorari, D., \& Shaw, P. (2012). Types of student intertextuality and faculty attitudes. Journal of Second Language Writing, 21(2), 149-164.

Pennycook, A. (1996). Borrowing others' words: Text, ownership, memory, and plagiarism. TESOL Quarterly, 30(2), 210-230.

Pennycook, A. (1998). English and the discourses of colonialism. London and New York: Routledge.

Penrose, A., \& Geisler, C. (1994). Reading and writing without authority. College Composition and Communication, 45(4), 505-520.

Petrić, B. (2007). Rhetorical functions of citations in high- and low-rated master's theses. Journal of English for Academic Purposes, 6(3), 238-253.

Petrić, B. (2012). Legitimate textual borrowing: Direct quotation in L2 student writing. Journal of Second Language Writing, 21(2), 102-117.

Roig, M. (1997). Can undergraduate students determine whether text has been plagiarized? The Psychological Record, 47, 113-122.

Roig, M. (2001). Plagiarism and paraphrasing criteria of college and university professors. Ethics \& Behavior, 11(3), 307-323.

Schembri, N. (2009). Citation practices: Insights from interviews with six undergraduate students at the University of Malta. University of Reading Language Studies Working Papers, 1, 16-24.

Shi, L. (2010). Textual appropriation and citing behaviours of university undergraduates. Applied Linguistics, 31(1), 1-24.

Shi, L. (2012). Rewriting and paraphrasing source texts in second language writing. Journal of Second Language Writing, 2(2), 134-148.

Sowden, C. (2005). Plagiarism and the culture of multilingual students in higher education abroad. ELT Journal, 59(3), 226-233.

Swales, J. M. (1990). Genre analysis: English in academic and research settings. Cambridge: Cambridge University Press.

Thompson, C. (2005). 'Authority is everything': A study in the politics of textual ownership and knowledge in the formation of student writer identities. International Journal for Educational Integrity, 1(1).

Wheeler, G. (2009). Plagiarism in the Japanese universities: Truly a cultural matter? Journal of Second Language Writing, 18(1), 17-29. 


\section{Acknowledgements}

I would like to thank the students who generously gave their time to participate in this study and the two anonymous reviewers who provided feedback on an earlier draft of this paper.

\section{About the author}

Sharon McCulloch has taught English as a Foreign Language, business English and English for Academic Purposes in Central Europe, Japan and the UK. She currently teaches various linguistics courses and is Academic Coordinator of the EAP/Study Skills Programme at Lancaster University in the UK, where she is also pursuing her $\mathrm{PhD}$ studies. Her research interests include EAP and second language reading and writing. 